\title{
Üvez Meyvesinin Antioksidan Aktivitesi
}

\author{
Yüksel Bayram ${ }^{*}$, Yasemin Torlak², Osman Sağdıç ${ }^{3}$ \\ ${ }^{1}$ Pamukkale Üniversitesi Çal Meslek Yüksekokulu Gıda İşleme Bölümü, (ORCID: 0000-0002-1130-577X) \\ ${ }^{2}$ Pamukkale Üniversitesi Çal Meslek Yüksekokulu Organik Tarım Bölümü, (ORCID: 0000-0001-5964-2532) \\ ${ }^{3}$ Yıldız Teknik Üniversitesi, Kimya Metalurji Fakültesi, Gıda Mühendisliği Bölümü, (ORCID: 0000-0002-2063-1462)
}

(İlk Geliş Tarihi 10 Temmuz 2019 ve Kabul Tarihi 18 Ağustos 2019)

(DOI: 10.31590 /ejosat.589736)

ATIF/REFERENCE: Bayram, Y., Torlak, Y. \& Sağdıç, O. (2019). Üvez Meyvesinin Antioksidan Aktivitesi. Avrupa Bilim ve Teknoloji Dergisi, (16), 933-939.

$\ddot{O} \mathbf{z}$

Yüzyıllardan beri, bütün ülkelerde tıbbi açıdan önemli olan çeşitli meyveler, hastalıkların tedavisi amacıyla kullanılmaktadır. Bu meyveler arasında üvez (Sorbus aucuparia) meyvesinin son zamanlarda antioksidan aktivitesi dikkat çekmektedir. Türkiye 'de doğal olarak yetişen Kuş üvezi meyvesinin insan sağllğ̆ açısından önemli biyoaktif bileşenler içerdiği yapılan çeşitli araştırmalarla belirlenmiş̧ir. Yaygın olarak reçel yapımında değerlendirilen bu meyvenin sağlık ve gıda sektörlerinde kullanım potansiyelinin araştırılması önem arz etmektedir.

Bu çalışmada, farklı çözücüler kullanılarak ultrason destekli ekstraksiyonla elde edilen üvez meyvesi ekstraktlarının, toplam fenolik ve flavonoid miktarları ile antioksidan aktiviteleri belirlenmiştir. Çalışmada Denizli 'nin Çal İlçesi'den toplanan üvez meyveleri kurutulduktan sonra öğütülmüş ve ultrason destekli ekstraksiyon yöntemi ile üç farklı çözücü içerisinde ekstrakte edilmiştir. Ekstraksiyon işlemi için etanol:su (1:1), metanol:su (1:1), aseton:su (1:1) çözeltileri kullanılmış ve her solvent için ayrı ayrı ultrasonik su banyosunda $50 \pm 5^{\circ} \mathrm{C}$ sıcaklıkta 40 dakika süreyle ekstraksiyon işlemleri gerçekleştirilmiş ve biyoaktif değerleri incelenmiş̧ir. Çalışmada, ekstrakt verimi, toplam fenolik ve flavonoid madde ile DPPH yöntemiyle antioksidan aktivite değerlerinin en iyi çıktığı çalışma koşulları, herbir ekstrakt elde etme yöntemine göre açıklanmış ve en iyi sonucun etanol:su karışımına (1:1) ait olduğu görülmüştür.

Anahtar Kelimeler: Üvez, Sorbus aucuparia, fenolik madde, antioksidan kapasite

\section{Antioxidant Activity of Uvez Fruit}

\begin{abstract}
For centuries, a variety of medicinally important fruits have been used in all countries to treat diseases in public health. Among these fruits, the antioxidant activity of rowan fruit has recently attracted attention. Rowan fruit (Sorbus aucuparia) of naturally grown plants in Turkey are determined by studies that contain important bioactive components in terms of human health. It is important to investigate the potential use of this fruit which is widely used in jam making in health and food sectors. The aim of this study was to investigate the total phenolic and flavonoid contents and antioxidant activities of rowan fruit extracts obtained under different extraction conditions.

In this study, rowan fruits collected from Çal region (Denizli, Turkey) were grinded after drying and extracts were obtained in three different solvents by ultrasound assisted extraction method. Ethanol:water (1:1), methanol:water (1:1), acetone:water (1:1) solutions were used for extraction and extraction was carried out for 40 minutes in an ultrasonic water bath at $50 \pm 5^{\circ} \mathrm{C}$ for each solvent separately and bioactive values were examined. In this study, extract yield, total phenolic, flavonoid substance and DPPH method with antioxidant activity values were found to be the best working conditions were explained according to extraction method and the best result was found to be ethanol: water mixture (1:1).
\end{abstract}

Keywords: Rowanbery, Sorbus aucuparia L., phenolic substance, antioxidant capacity

* Sorumlu Yazar: Pamukkale Üniversitesi Çal Meslek Yüksekokulu Gıda İşleme Bölümü, Denizli, Türkiye, (ORCID: 0000-0002-1130-577X), ybayram@pau.edu.tr 


\section{Giriş}

Bitkilerde bulunan fenolik bileşikler, insan beslenmesinin önemli bir parçasıdır ve antioksidan özelliklerinden dolayı büyük ilgi çekmektedir. Meyve ve sebzeler insan diyetindeki en önemli fenolik bileşik kaynaklarıdır. Bu bileşikler, anti-alerjenik, anti-aterojenik, anti-enflamatuar, anti-mikrobiyal, antioksidan, anti-trombotik, kardiyo-koruyucu ve vazodilatuar etkiler gibi çok çeşitli fizyolojik özellikler sergilemektedir. Fenolik bileşiklerden elde edilen faydalı etkiler, antioksidan aktivitelerine dayandırılmaktadır (Balasundram ve ark., 2006).

Rosaceae familyasına ait yabani bir meyve olan üvez (Sorbus aucuparia), Türkiye'nin farklı bölgelerinde yabani olarak yetişmektedir. Mayıs-Haziran aylarında beyaz, pembe renkli çiçekler açan bitkinin, meyveleri Ağustos ve Eylül aylarında hasat edilmektedir. Üvez cinsinin, ülkemizde 12 türü ve 17 taksonu bulunmaktadır. Sorbus aucuparia L. (kuş üvezi), Sorbus domestica L. (has üvez), Sorbus umbellata (ak üvez) ve Sorbus torminalis L. (akçaağaç yapraklı üvez) en önemli üvez türleridir (Korkut ve ark., 2010). S. aucuparia (kuş üvezi), 15-20 m. boylanabilen, özel bir toprak ve iklim isteği olmayan bir orman ağacıdır. Bu ağaç, kurak ibreli ormanlarda yetişebildiği gibi, nemli ılıman yapraklı ormanlarda da yaygın olarak görülen, gölgeye dayanıklı, meyveleri kırmızı olan bir türdür (Korkut ve ark., 2010). Sorbus türleri gibi yenilebilir meyveleri olan bazı süs bitkileri, çevresel (kuşlar için yiyecek, şehir parklarında dekorasyon), sağlığa yararlı (biyolojik olarak aktif bileşikler içermesi) ve aynı zamanda beslenmede de önemli işlevlere sahip olabilir.

Yapılan araştırmalara göre, üvez meyvesi, fenolik bileşik kompleksleri nedeniyle, antioksidan, immünotropik, anti-enflamatuar ve kılcal güçlendirici etkiler göstermektedir (Isaikinave ark., 2018). Bu meyveler, geleneksel tıpta, kronik ishal, karaciğer ve safra kesesinin çeşitli hastalıklarının tedavisi için, ayrıca Yunanistan'da antidiyabetik ajan olarak kullanılmaktadır. Besleyici ve tıbbi özellikleri nedeniyle, S. aucuparia geleneksel olarak reçel ve jöle hazırlanmasında da değerlendirilmektedir (Šavikin ve ark., 2017). Fructus Sorbi aucupariae, resmen tanınmış bir farmasötik hammaddedir ve bir polivitamin ilacı olarak vitamin karışımının bileşeni olarak yer almaktadır. Üvez meyveleri $\mathrm{C}, \mathrm{B}_{2}$, E vitamin kompleksleri ile karotenoidler içermektedir. Ayrıca fenolik bileşikler (antosiyaninler, fenolik asitler, flavonoidler), polisakkaritler (pektin maddeler ve serbest şekerler), siyanojenik bileşikler, organik asitler, iz ve majör mineral elementleri içerir (Isaikina ve ark., 2018). Üvez meyvesinin çeşitlerinde kampferol, kuersetin, mirisetin ve bunların glikozitleri gibi flavonoidler, kafeik, p-kumarik ve ferulik asit gibi hidroksinamik asitler ile p-hidroksibenzoik ve gallik asit gibi hidroksibenzoik asitler bulunmaktadır. Meyvede bulunan başlıca bileşenler ferulik asit, kuersetin ve mirisetindir (Razina ve ark., 2006).

Bu çalışma ile ülkemizde doğal olarak yetişen (Denizli yöresine ait) ve son yıllarda üzerinde birçok çalışma yapılarak dünya üzerinde ticari önemi artacağına inanılan üvez meyvesinin farklı çözücülerde ultrason destekli ekstraksiyon yöntemi ile ekstrakte edilmesi, toplam fenolik ve flavonoid madde miktarları ile antioksidan kapasitesinin tespit edilerek, tüm ekstraksiyon denemeleri için en uygun çözücünün belirlenmesi hedeflenmiştir.

\section{Materyal ve Metot}

\subsection{Materyal}

Araştırma materyalini Çal yöresinden (Denizli, Türkiye) ekim ayında toplanan üvez bitkisinin meyveleri oluşturmuştur. Bu meyveler kurutulmuş, ögütülmüş ve çözgen ekstraksiyonuna tabi tutulmuştur. Analizlerde, hassas terazi (Sartorius TE2145), spektrofotometre (Shimadzu UV-1800, Japonya), ultrasonik su banyosu (WiseClean, DH.WUC.D10H, Almanya), öğütücü (Siemens, Almanya), santrifüj (Universal 32R) ve etüv (Memmert) kullanılmıştır. Kimyasallar maddeler olan Folin-Ciocalteu reaktifi, 2,2difenil-1-pikril hidrazil (DPPH), gallik asit, kateşin, BHT (Bütillenmiş Hidroksi Toluen) etanol, metanol, aseton, sodyum hidroksit, sodyum karbonat, sodyum nitrit $\left(\mathrm{NaNO}_{2}\right)$, Alüminyum klorür, hidrojenklorür Sigma-Aldrich (Almanya) ve Merck (Almanya) firmalarından temin edilmiştir.

\subsection{1. Örneklerin Hazırlanmast}

Laboratuvara getirilen taze üvez meyveleri $45^{\circ} \mathrm{C}$ sıcaklıktaki etüvde kurutulmuştur. Numuneler kurutulduktan sonra, öğütülerek analiz edilinceye kadar hava almayacak şekilde ambalajlanarak, $4^{\circ} \mathrm{C}$ 'de karanlık ortamda muhafaza edilmiştir.

\subsubsection{Ekstraktların Hazırlanması}

Öğütülmüş kuru üvez meyvesinin biyoaktif bileşenleri $100 \mathrm{KHz}$ sabit frekansta ultrasonik su banyosunda (WiseClean, DH. WUC.D10H, Almanya) ekstrakte edilmiştir. Ekstraksiyon işleminde, çözücü olarak etanol:su (1:1), metanol:su (1:1) ve aseton:su (1:1) kullanılmıştır. 1:10 (örnek:çözücü) oranında hazırlanan çözeltiler ultrasonik su banyosunda $50 \pm 5^{\circ} \mathrm{C}$ sicaklıkta $40 \mathrm{dk}$ işleme tabi tutulmuştur. 3 farklı çözücü ile hazırlanan örnekler kaba filtreden geçirildikten sonra 4100 rpm'de (rpm) 10 dakika (Hettich 320R, Almanya) santrifüjlenmiştir. Ekstraktlar analiz edilinceye kadar amber renkli cam şişede $-18{ }^{\circ} \mathrm{C}$ 'de depolanmış ve antioksidan aktiviteleri karşılaştırmalı olarak incelenmiştir (Stalikas ve ark., 2007; Dai ve ark., 2010). 


\subsection{Ekstrakt Verimlerinin Tayini}

Denemeler esnasında hazırlanan ekstraktlar petri kaplarına aktarılarak, $45^{\circ} \mathrm{C}$ 'de kurumaya bırakılmış ve belirlenen kurutulmuş ekstrakt miktarı ile başlangıçtaki meyvenin kuru maddesine göre ekstrakt verimi hesaplanmıştır. Ekstrakt verim hesabı Eşitlik 2.1'e göre yapılmıştır.

$\%$ Verim $=\frac{\text { Elde edilen kuru ekstrakt miktarı }}{\text { Meyve kurumadde miktarı }} * 100$

Eşitlik 2.1

\subsection{Toplam Fenolik Madde Tayini}

Toplam fenolik madde miktarı Singleton ve Rossi (1965) tarafından geliştirilen ve Li ve ark. (2006) tarafından modifiye edilen metot esas alınarak gerçekleştirilmiştir. FCR (Folin Fenol Reaktifi veya Folin-Denis reaktifi), fosfomolibdat ve fosfotungstat karışımı bir reaktif olup, fenolik, polifenolik antioksidanların kolorimetrik olarak tayininde kullanılır.

Ekstrakte edilen numuneler damıtılmış su ile 1:10 oranında seyreltilmiş ve $0.5 \mathrm{~mL}$ seyreltilmiş ekstraktlara 2,5 mL Folin-Ciocalteu reaktifi $(0,2 \mathrm{~N})$ eklenmiştir. Daha sonra, reaksiyon tüpüne $2 \mathrm{~mL} \%$ 7,5 $\mathrm{Na}_{2} \mathrm{CO}_{3}$ ilave edilmiştir. Hazırlanan karışımlar oda sıcaklığında 30 dakika karanlık ortamda bekletildikten sonra, numunelerin absorbansı spektrofotometre (Shimadzu 150 UV-1800 spektrofotometre, Japonya) (Singleton ve Rossi, 1965) kullanılarak 760 nm'de ölçülmüştür. Sonuçlar gallik asit eşdeğeri (GAE), mg GAE/L olarak verilmiştir. Her bir örnek üç kez analiz edilmiş olup, sonuçlar üç tekrarlı ölçümlerin ortalaması olarak gösterilmiştir.

\subsection{Toplam Flavonoid Tayini}

Numunelerin toplam flavonoid içeriği, Zhishen ve ark. (1999) tarafindan açıklanan yönteme göre belirlenmiştir. $1 \mathrm{~mL}$ numune ekstraktları $4 \mathrm{~mL}$ distile su ile kanştınlarak üzerine $0,3 \mathrm{~mL} \mathrm{NaN0}_{2}$ (distile suda \%5) eklenmiş ve $5 \mathrm{dakika}$ sonra $0,3 \mathrm{~mL} \mathrm{AlCl}_{3}$ (suda\%10) ilave edilmiştir. Karışım 6 dakika inkübe edildikten sonra, $2 \mathrm{~mL} 1 \mathrm{M} \mathrm{NaOH}$ çözeltisi ilave edilmiş ve karışım, damıtılmış su ile 10 mL'ye ayarlanmıştır. Daha sonra, numunelerin absorbansı spektrofotometre kullanılarak 510 nm'de ölçülmüştür. Sonuçlar kateşin eşdeğeri (CAE), mg CAE/L olarak verilmiştir. Her bir örnek üç kez analiz edilmiş olup, sonuçlar üç tekrarlı ölçümlerin ortalaması olarak gösterilmiştir.

\subsection{Antioksidan Kapasite Tayini, DPPH Yöntemi (Serbest Radikal Yakalama)}

Örneklerin antioksidan kapasiteleri Sanchez-Moreno ve ark. (2002), tarafından geliştirilen yönteme göre belirlenmiştir. Bu metod antioksidanların kararlı ve sentetik DPPH (2,2-difenil-1-pikril hidrazil) radikalini süpürücü etkilerini ölçmeye dayalı bir yöntemdir. Koyu mor renkli bir radikal olan olan DPPH 517 nm'de maksimum absorbans verir. Ortamda antioksidan bulunduğunda, antioksidan tarafından indirgenip rengi açılarak DPPH indirgenmiş molekülüne dönüşür ve absorbansı azalır. Antioksidanların radikal süpürme kabiliyetlerini değerlendiren kolay ve hızlı bir yöntemdir. Yaklaşık 0,1 mL örnek, 4,9 mL DPPH çözeltisi ile karıştırılmış ve karanlıkta 30 dakika oda sıcaklığında inkübe edilmiştir. Numunelerin absorbansı, inkübasyon süresinin sonunda spektrofotometre (Shimadzu UV-1800 spektrofotometresi, Japonya) ile 517 nm'de ölçülmüştür (Singleton \& Rossi, 1965; Sánchez-Moreno, 2002). Standart olarak BHT (Bütillenmiş Hidroksi Toluen) kullanılmıştır. Her bir uygulamaya ait örneğin, DPPH radikalini inhibe oranları (\%inhibisyon) Eşitlik 2.2'ye göre hesaplanmıştır.

DPPH İnhibisyonu $(\%)=[($ Ac-As $) / A c x ~ 100]$

Eşitlik 2.2

Ac; kontrol absorbans1,

As; örneklerin absorbansı

Ac çözeltisinin içinde meyve ekstraktı bulunmadığı için örnekler Ac çözeltisi ile kıyaslanarak yorumlanmaktadır. Antioksidanların serbest radikalleri süpürme etkisinden dolayı örneklerin absorbansı değerlerinin Ac'den düşük çıkması beklenmektedir. Her bir örnek üç kez analiz edilmiş olup, sonuçlar üç tekrarlı ölçümlerin ortalaması olarak gösterilmiştir (Kumaran ve Joel Karunakaran, 2007).

\section{6. İstatistiksel Analiz}

Araştırma sonuçları SPSS (PASW Statistics 18) istatistik programı ile incelenmiştir. Sonuçlar 3 tekrarlı ölçümlerin ortalaması \pm standart sapma olarak gösterilmiştir. Elde edilen bulgular tek yönlü varyans analizi ve Duncan testi ile değerlendirilerek uygulamalar arasındaki farklılıklar 0.05 güven aralığında verilmiştir. 


\section{Araştırma Sonuçları ve Tartışma}

\subsection{Ekstraksiyon Yöntemlerinin Karşılaştırılması}

Yöntemler karşılaştırlırken, etanol:su (1:1), metanol:su (1:1) ve aseton:su (1:1) çözücüleriyle elde edilen ekstraktların kurutulmasıyla maksimum kuru madde üzerinden hesaplamalar yapılmıştır. Bu değerlendirmelere göre elde edilen sonuçlar Tablo 1'de gösterilmiştir.

Tablo 1. Üvezden farkl çözücülerle elde edilen ekstraktlara ait verimlerin karşılaştırllması

\begin{tabular}{cc}
\hline Çözücü cinsi & Ekstrakt verimi (mg ekstrakt/g kuru meyve) \\
\hline Etanol:su (1:1) & $332 \pm 10^{\mathrm{c}}$ \\
Metanol:su (1:1) & $301 \pm 12^{\mathrm{b}}$ \\
Aseton:su (1:1) & $228 \pm 09^{\mathrm{a}}$
\end{tabular}

* Üç paralel analizin ortalaması \pm standart sapma.

*Aynı sütunda gösterilen farklı harfler one way ANOVA Duncan testine göre farklı çözücülerin verim üzerindeki etkisinin istatistiksel olarak önemli $(\mathrm{p}<0,05)$ olduğunu göstermektedir.

Farklı çözücülerle elde edilen ekstraktların verimleri etanol:su (1:1), metanol:su (1:1) ve aseton:su (1:1) çözücüleri için sırasıyla 332, 301 ve 228 (mg ekstrakt/g kuru meyve) olarak bulunmuştur. Buna göre, ultrason destekli ekstraksiyon yönteminde çözücü maddelerin verim üzerine etkileri incelendiğinde üç farklı çözücü açısından en yüksek performans, etanol:su (1:1) karışımının çözücü olarak kullanıldığı denemelerde elde edilmiştir. Ektraksiyon verimi en düşük aseton:su çözücüsünde açığa çıkmıştır. Bu çalışmada farklı çözücülerin ekstrakt verimi üzerine etkisinin istatistiki olarak önemli $(\mathrm{p}<0,05)$ olduğu saptanmıştır.

Fenolik madde ekstraksiyonunda değişik çözücülerin kullanıldığı çalışmalarda etanol (Generalic ve ark., 2011), metanol (Perez ve ark., 2011), aseton (Salem ve ark., 2013), dietileter, hegzan (Roby ve ark., 2013) ve su (Martins ve ark., 2015) gibi çözücülerin ekstraksiyon verimi üzerinde değişiklik gösterdiği rapor edilmektedir. Yapılan çalışmalarda ekstraksiyon veriminde çözücü etkisinin çözücünün polaritesine bağlı olarak değiştĭgi belirtilmektedir. Roby ve ark. (2013) bazı tıbbi bitkilerin toplam fenolik madde ve antioksidan aktivitesini inceledikleri çalışmada çözücü olarak metanol, etanol, aseton ve hekzan çözücülerini kullanmışlar ve çözücülerin etkisini methanol $>$ etanol $>$ aseton $>$ hekzan olarak raporlamışlardır.

\subsection{Toplam Fenolik ve Flavonoid Madde Bulguları}

$\mathrm{Bu}$ çalış̧mada toplam fenolik madde tayini, Folin-Ciocaltaeu metoduna göre yapılmıştır. Farklı solventlerle (etanol:su (1:1), metanol:su (1:1), aseton:su (1:1)) hazırlanan ekstraktlarının Folin-Ciocalteu'nun fenol reaksiyonuna göre toplam fenolik madde miktarları tespit edilmiştir. Gallik asit standart bileşik olarak kullanılmıştır. Bunun için, gallik asitin 5-120 ppm konsantrasyon aralığındaki 6 farklı konsantrasyonu ile her çözücü için kalibrasyon eğrileri elde edilmiştir (Şekil 1).
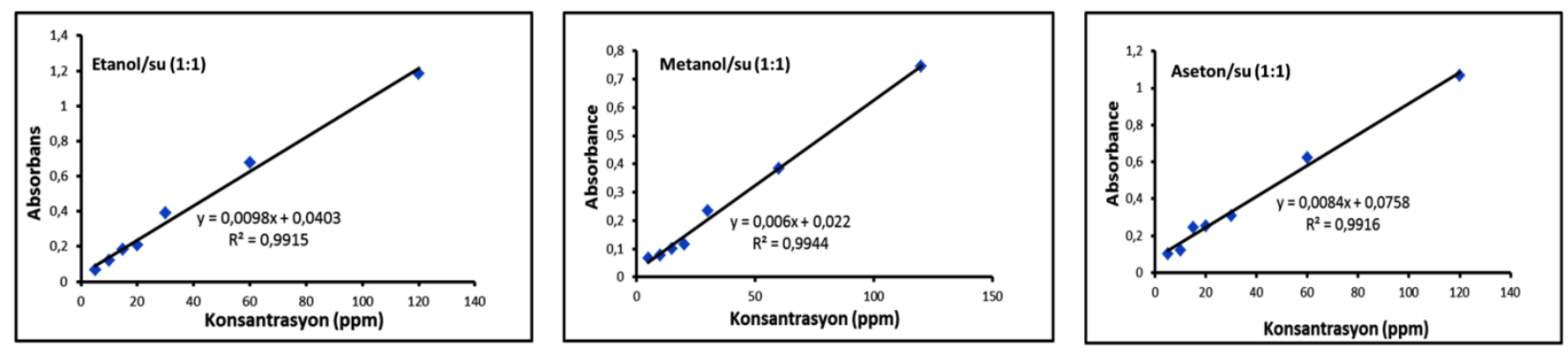

Şekil 1. Farklı çözücülerdeki gallik asit kalibrasyon ĕgrileri

Üvezin farklı ekstraktlarında bulunan toplam fenolik madde miktarları Şekil 1'de verilen gallik asitin kalibrasyon eğrilerinden elde edilen denklemlerden gallik asite eşdeğer olarak hesaplanmıştır. Her bir örnek üç kez analiz edilmiş olup, sonuçlar üç tekrarlı ölçümlerin ortalaması olarak gösterilmiştir.

Eğrilerin regresyon eşitliklerine göre hesaplanan örneklerdeki toplam fenolik bileşik miktarları etanol, metanol ve aseton için sırasıyla 19,25, 11,83, 15,84 mg GAE/g olarak belirlenmiştir (Tablo 2). Araştırma sonuçlarına göre en yüksek toplam fenolik madde miktarı, 19,25 mg GAE/g değeri ile alkol:su (1:1) ekstraklarının gösterdiği ve sonuçların çözücü farklılığına bağlı olarak değiştiği tespit edilmiştir. Toplam fenolik madde miktarının çözücü farklılığına göre sıralaması etanol:su ekstraktı > aseton:su ekstraktı > metanol:su ekstraktı şeklinde bulgulanmıştır. Toplam fenolik madde ve antioksidan aktivite için ekstraksiyon veriminde de olduğu gibi etanol:su (1:1) karışımının kullanıldığı denemeler en iyi sonucu vermiştir Meyve ekstraklarının eldesinde farklı çözücülerin kullanıldığı bu araştırmada, toplam fenolik madde değeri üzerinde çözücü etkisinin istatistiksel açıdan önemli $(\mathrm{p}<0,05)$ olduğu belirlenmiştir. 
Tablo 2. Üvez meyvesinin ekstrakt verimi, toplam fenolik, flavanoid madde ve antioksidan aktivitenin çözücü cinsine göre değişimi

\begin{tabular}{lccc}
\hline Çözücü cinsi & $\begin{array}{c}\text { Toplam Fenolik } \\
\text { Madde (mg GAE/g) }\end{array}$ & $\begin{array}{c}\text { Toplam Flavanoid } \\
\text { Madde (mg CAE/g) }\end{array}$ & $\begin{array}{c}\text { Antioksidan aktivite } \\
\text { DPPH (\%inhibisyon) }\end{array}$ \\
\hline Etanol:su (1:1) & $19,25 \pm 0,10^{\mathrm{a}}$ & $5,16 \pm 0,42^{\mathrm{c}}$ & $92,18 \pm 10,01^{\mathrm{a}}$ \\
Metanol:su (1:1) & $11,83 \pm 0,22^{\mathrm{b}}$ & $3,75 \pm 0,35^{\mathrm{d}}$ & $63,61 \pm 09,24^{\mathrm{b}}$ \\
Aseton:su (1:1) & $15,84 \pm 0,15^{\mathrm{c}}$ & $7,33 \pm 0,21^{\mathrm{e}}$ & $64,74 \pm 12,16^{\mathrm{b}}$ \\
\hline
\end{tabular}

* Üç paralel analizin ortalaması \pm standart sapma.

*Aynı sütunda gösterilen aynı harfler çözücüler arasındaki farkın one way ANOVA Duncan testine göre istatistiksel olarak önemli olmadığııı (p>0,05) gösterirken, farklı harfler farkın istatistiksel olarak önemli $(\mathrm{p}<0,05)$ olduğunu göstermektedir.

Mevcut çalışmaya benzer şekilde, Kahkönen ve ark. (1999) tarafından yapılan çalışmada liyofilize edilmiş üvezin toplam fenolik

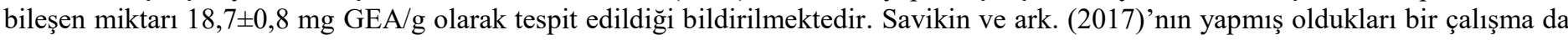
$\% 50$ etanollu su ile ekstrakte ettikleri Sorbus aquparianın toplam fenolik madde miktarını yapmıș olduğumuz çalışmaya benzer şekilde 5,25- 15,91 mg GAE/g km olarak belirlemişlerdir. Tian ve ark. (2018), etanol:su:asetik asit, (70:30:1) çözücü karışımında ekstrakte ettikleri üvezin toplam fenolik madde miktarını 45,6 GAE mg/100 mL olarak bulgulamışlardır. Yenilebilir bitkiler içinde en yüksek antioksidan aktiviteyi üzümsü meyveler göstermektedir. Üzümsü meyvelerin içerdiği fenolik madde miktarları 12,4-50,8 mg/g arasında değişmektedir (Kahkönen ve ark., 1999). Frenk üzümü, ahududu gibi mor renkli üzümsü meyveler (28,7-50,8 mg/g), üvez meyvesinden $(19,25 \mathrm{mg} / \mathrm{g})$ daha fazla fenolik bileşen içermektedir. Velioğlu ve Mazza (1991) olgunlaşmış üvez meyvesinin toplam fenolik madde miktarını, $90,90 \mathrm{mg} / 100 \mathrm{~g}$ olarak belirlemiştir. Bir başka çalışma da ise üvezin toplam fenolik madde miktarı 484,9 $\mathrm{mg} / 100 \mathrm{~g}$ olarak tespit edilmiştir (Mikulic-Petkovsek ve ark., 2012).

Farklı çözücülerin kullanıldığı ekstraktların toplam flavonoid miktarları hesaplamasında standart olarak kullanılan kateşinin 5-120 ppm konsantrasyon aralığındaki 6 farklı konsantrasyonu ile her çözücü için kalibrasyon eğrileri elde edilmiştir (Şekil 2).
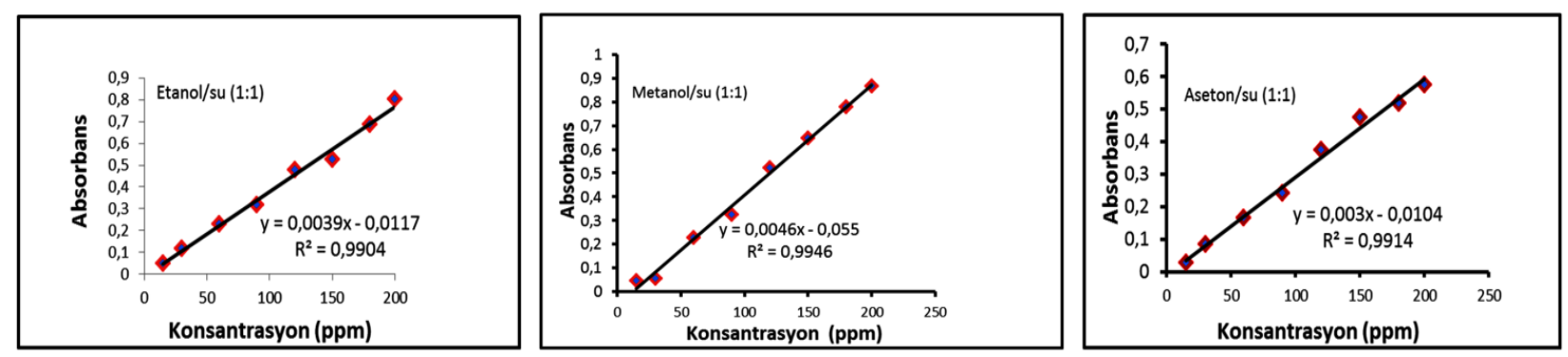

\section{Şekil 2. Farklı çözücülerdeki kateşinin kalibrasyon ĕgrileri}

Üvezin farklı ekstraktlarında bulunan toplam flavonoid madde miktarları Şekil 2'de verilen kateşinin kalibrasyon eğrilerinden elde edilen denklemlerden kateşine eşdeğer olarak hesaplanmıştır. Her bir örnek üç kez analiz edilmiş olup, sonuçlar üç tekrarlı ölçümlerin ortalaması olarak gösterilmiştir.

Üvezin etanol:su (1:1), metanol:su (1:1) ve aseton:su (1:1) çözücülerindeki toplam flavonoid madde miktarları kateşin cinsinden sırasıyla 5,16, 3,75, 7,33 mg CAE/g olarak belirlenmiștir (Tablo 2). Buna göre en yüksek toplam flavonoid madde miktarı, 7,33 mg $\mathrm{CAE} / \mathrm{g}$ değeri ile aseton:su (1:1) ekstraklarının gösterdiği ve sonuçların çözücü farklılığına bağlı olarak değiştiği görülmüştür. Toplam flavonoid madde miktarlarının çözücü farklılığına göre sıralaması aseton:su ekstraktı > etanol:su ekstraktı > metanol:su ekstraktı şeklinde tespit edilmiştir. Üvez ekstraklarının eldesinde farklı çözücülerin kullanıldığı bu araştırmada, toplam flavonoid madde üzerinde çözücü etkisi istatistiksel açıdan önemli $(p<0,05)$ bulunmuştur. Şen (2011)'in Sorbus domestica'nın su ile hazırladıkları ekstraktların flavonoid miktarlarını belirledikleri bir çalışmada üvezin toplam flavonoid miktarları 112,10- 463,10 $\mu \mathrm{g} / \mathrm{mL} \mathrm{kateşin}$ ekivalenti olarak rapor edilmiştir. Gil-Izquierdo ve Mellenthin (2001) tarafından yapılan bir başka çalışmada üvez ekstraktında kuersetin eşdeğeri olarak tespit edilen toplam flavonol miktarı $291 \mathrm{mg} / \mathrm{L}$ ' dir. Üvez meyvesinde bulunan başlıca fenolik bileşikler ferulik asit, kuersetin ve mirisetindir. Üzümsü meyvelerde bulunan fenolik bileșik olan kuersetin üvez meyvesinde $50 \mathrm{mg} / \mathrm{kg}$ 'dan fazla bulunmaktadır. Üvez meyvesiyle yapılan çalışmalarda 6 kuersetin, 2 kampferol glikozidi olmak üzere 8 flavonol belirlenmiştir (Del Rio ve ark., 2010).

\subsection{DPPH Serbest Radikal Giderme Aktivitesi Bulguları}

Serbest radikal olan DPPH (2,2-difenil-1-pikril hidrazil) antioksidan maddelerin radikal giderme aktivitelerini belirlemek için en sık kullanılan bileşiklerdendir. Yoğun mor renkli DPPH çözeltisi, antioksidan kapasiteye sahip bileşen ile karıştırıldığında, 
antioksidan bileşikten bir hidrojen atomu alarak stabil, radikal olmayan sarı renkli DPPH formuna dönüşmektedir (Brand-Williams ve ark., 1995; Chen ve ark., 2013).

Bitkiler, kimyasal yapı ve biyolojik özellikler bakımından geniş ölçüde farklılık gösteren güçlü doğal antioksidan kaynağı oluşturmaktadır. S. aucuparia (kuş üvezi) ve $S$. domestica gibi bazı Sorbus türlerinin yenilebilir meyveleri, biyolojik etkinlikleri nedeniyle geleneksel tıpta kullanılan terapötik özellikleri ile bilinmektedir (Savikin ve ark., 2017). Bu çalışmada, antioksidan aktivitesi \% inhibisyon olarak yapılan hesaplamalara göre, meyvelerin etanol-su (1:1), metanol-su (1:1) ve aseton-su (1:1), ekstraktları $\left(0,1 \mathrm{mg} \mathrm{ml}^{-1}\right)$ için sırasıyla \%92,18, \%63,61 ve \%64,74 olarak belirlenmiştir (Tablo 2). Ekstraklarının eldesinde farklı çözücülerin kullanıldığı bu araştırmada, antioksidan aktivite üzerinde çözücü etkisinin bütün gruplar arasındaki farkın istatistiki olarak önemli $(\mathrm{p}<0,05)$ olduğu, metanol:su ve aseton:su arasındaki farkın istatistiki olarak önemli olmadığı $(\mathrm{p}>0,05)$ bulgulanmıştır. Tüm ekstraktların yüksek derecede inhibitör aktivite (>\% 60) sergilediği tespit edilmiş̧tir. Ekstraktlar arasında en yüksek DPPH inhibisyon aktivitesini, \%92,18 değeri ile alkol-su (1:1) ekstraklarının gösterdiği ve sonuçların çözücü farkl1lı̆̆ına bağl1 olarak değiştiği görülmüştür. Alkol:su üvez ekstraktının \% inhibisyon değerinin standart olarak kullanılan BHT’nin serbest radikal giderim aktivitesiyle $(\% 86,32)$ karşılaştırıldığında, alkollü üvez ekstraktının $0,1 \mathrm{~g} / \mathrm{mL}$ konsantrasyonunda BHT'den daha iyi antioksidan etki gösterdiği tespit edilmiştir. DPPH serbest radikali inhibisyon aktivitesinin çözücü farklılı̆̆ına göre sıralaması etanol:su ekstraktı > aseton:su ekstraktı > metanol:su ekstraktı şeklinde belirlenmiş̧ir. Araştırma sonuçlarına göre, farklı çözücülerin kullanıldığı üvez ekstraktlarının toplam fenolik madde miktarı artışına bağlı olarak antioksidan kapasiteleri de artış göstermektedir. Mevcut çalışmaya benzer şekilde, Şen (2011)'in aynı konsantrasyonda hazırladığı çözeltiler ile Sorbus domestica'nın antioksidan aktivitesini belirlediği çalışma da \% DPPH radikali giderim aktivitesini \%84,88 olarak bulgulamıştır. Tian ve ark. (2018) 'nın yapmış oldukları başka bir çalışma da etanol:su:asetik asit, (70:30:1) çözücü karışımında ekstrakte ettikleri üvezin DPPH inhibisyon değerlerini \%15,0- 38,7 aralığında rapor etmişlerdir. Lüle ve Koyuncu (2015) üvez (Sorbus domestica L.) meyvesi ile çiçeğinin su ve aseton kullanarak hazırladıkları ekstraktlarının antioksidan aktivitelerini belirledikleri çalışmada, DPPH radikali giderme aktivitesi tayininde, ekstraktlar arasında en iyi aktiviteyi üvez meyvesinin sulu ekstraktının gösterdiğini, ferrik tiyosiyanat (FTC) metoduyla toplam antioksidan kapasitesi tayininde ise üvez çiçeğinin aseton (\%84.97) ekstraktının en yüksek aktiviteye sahip olduğunu tespit etmişlerdir.

\section{Sonuç ve Tartışma}

Meyve ve sebzelerde bulunan biyoaktif bileşenler insan sağlığını doğrudan etkilemektedir. Bitkilerden elde edilen polifenolik antioksidan bileşenlerin, serbest radikal olarak adlandırılan kararsız ve zararlı maddelerin etkilerini azalttı̆̆ı, yapılan bilimsel çalışmalar neticesinde bilinmektedir. Antioksidanlar bu özelliği sayesinde başta kanser olmak üzere, şeker hastalığı, kalp-damar hastalıkları gibi birçok hastalığın olumsuz etkilerini azaltmaktadır. Yapılan araştırmalarla, bitkisel kaynaklardan elde edilecek biyoaktif bileşenlerin günlük tüketimlerinin arttırılması ile bazı hastalıkların önlenebileceği görülmektedir.

$\mathrm{Bu}$ araştırmada, Çal yöresinde (Denizli) yetişen üvez meyvelerinin, ultrasonik su banyosu ile farklı çözücülerin kullanıldığı ekstratlarının toplam fenolik ve flavonoid madde miktarları ile antioksidan özellikleri (DPPH yöntemi) belirlenmiştir. Deney sonuçlarına göre en yüksek toplam fenolik madde miktarı 19,25 mg GAE/g değeri ile alkol:su (1:1) ekstraklarının gösterdiği ve sonuçların çözücü farklılığına göre istatistiki olarak önemli $(p<0,05)$ olarak değiştiği görülmüştür. Üvez meyvesine ait farklı çözücülerin kullanıldığı ekstraktlar arasında en yüksek toplam flavonoid madde miktarı, 7,33 mg CAE/g değeri ile aseton:su (1:1) ekstraklarının gösterdiği ve çözücü etkisinin önemli $(p<0,05)$ olduğu saptanmıştır. Bu deneyde antioksidan aktivite için belirlenen DPPH \% inhibisyon değerlerine göre en yüksek inhibisyon etkiyi etanollü ekstraktların göstediği ve sonuçların çözücü farklılığına bağlı olarak değiştiği tespit edilmiş̧ir $(\mathrm{p}<0,05)$. Sorbus aucuparia meyvesinin ve standart olarak kullanılan BHT'nin \% inhibisyon değerleri sırasıyla, \%92,18, \%86,32 olarak bulgulanmıştır. Antioksidan aktivite değerleri karşılaş̧ırıldığında Sorbus aucuparia'nın standart olarak kullanılan sentetik antioksidana göre daha yüksek sonuç verdiği görülmektedir. Genel bir değerlendirme yapıldığında çalışmada kullanılan üvez meyvesinin etanol ekstraktlarının diğer çözücülere göre daha fazla fenolik madde içerdiği ve daha yüksek DPPH radikalini giderme aktivitesine sahip olduğu tespit edilmiştir.

Kuş üvezi meyvelerinin yüksek oranda biyoaktif bileşenlere sahip olduğu ve bu değerlere bağlı olarak farmasötik ve gıda endüstrisinde potansiyel bir antioksidan kaynağı olarak kullanılabileceği sonucuna varılmıştır. Sağlık üzerinde önemli etkilere sahip, biyoaktif bileşenler bakımından zengin yabani meyvelerin hastalıkları önleme ve tedavisinde kullanımı üzerine daha fazla inceleme yapılması, ayrıca bu meyvelerin gıda bileşimlerindeki katkıları belirlenerek araştırmaların endüstriyel uygulamalara dönük devamlılık sağlanması önem arz etmektedir.

\section{Kaynakça}

Balasundram, N., Sundram, K., \& Samman, S. (2006). Phenolic compounds in plants and agri-industrial by-products: Antioxidant activity, occurrence, and potential uses. Food Chemistry. https://doi.org/10.1016/j.foodchem.2005.07.042.

Bondet, V., Brand-Williams, W., \& Berset, C. (1997). Kinetics and Mechanisms of Antioxidant Activity using the DPPH.Free Radical Method. LWT - Food Science and Technology, 30(6), 609-615. https://doi.org/10.1006/fstl.1997.0240.

Brand-Williams, W., Cuvelier, M. E., \& Berset, C. (1995). Use of a free radical method to evaluate antioxidant activity. LWT - Food Science and Technology. https://doi.org/10.1016/S0023-6438(95)80008-5.

Chen, Z., Bertin, R., \& Froldi, G. (2013). EC50 estimation of antioxidant activity in DPPH* assay using several statistical programs. Food Chemistry. https://doi.org/10.1016/j.foodchem.2012.11.001.

Dai, J., \& Mumper, R. J. (2010). Plant phenolics: Extraction, analysis and their antioxidant and anticancer properties. Molecules. 
https://doi.org/10.3390/molecules15107313.

Del Rio, D., Borges, G., \& Crozier, A. (2010). Berry flavonoids and phenolics: Bioavailability and evidence of protective effects. British Journal of Nutrition. https://doi.org/10.1017/S0007114510003958.

Generalic, I., Skroza, D., Ljubenkov, I., Katalinic, A., Burcul, F., Katalinic, V. (2011). Influence of the phenophase on the phenolic profile and antioxidant proterties of Dalmatian sage. Food Chemistry, 127, 427- 433.

Gil-Izquierdo, A., \& Mellenthin, A. (2001). Identification and quantitation of flavonols in rowanberry (Sorbus aucuparia L.) juice. European Food Research and Technology. https://doi.org/10.1007/s002170100328.

Isaikina, N. V., Kalinkina, G. I., Razina, T. G., Zueva, E. P., Rybalkina, O. Y., Ulirich, A. V., ... Shilova, A. B. (2018). Sorbus aucuparia L. Fruit Is a Source of the Drug for Increasing the Efficiency of Tumor Chemotherapy. Russian Journal of Bioorganic Chemistry. https://doi.org/10.1134/s1068162018070038.

Kähkönen, M. P., Hopia, A. I., Vuorela, H. J., Rauha, J. P., Pihlaja, K., Kujala, T. S., \& Heinonen, M. (1999). Antioxidant activity of plant extracts containing phenolic compounds. Journal of Agricultural and Food Chemistry. https://doi.org/10.1021/jf9901461.

Korkut; M. Budakci. (2010). The effects of high-temperature heat-treatment on physical properties and surface roughness of rowan (Sorbus aucuparial.) wood. Wood Research.

Korkut, S., Guller, B., Aytin, A., \& Kok, M. S. (2009). Turkey's Native Wood Species: Physical and Mechanical Characterization and Surface Roughness of Rowan (Sorbus aucuparia L.). Wood Research.

Kumaran, A., \& Joel Karunakaran, R. (2007). In vitro antioxidant activities of methanol extracts of five Phyllanthus species from India. LWT - Food Science and Technology. https://doi.org/10.1016/j.lwt.2005.09.011.

Lang, Q., \& Wai, C. M. (2001). Supercritical fluid extraction in herbal and natural product studies - A practical review. Talanta. https://doi.org/10.1016/S0039-9140(00)00557-9.

Lehotay, S. J. (1997). Supercritical fluid extraction of pesticides in foods. Journal of Chromatography A. https://doi.org/10.1016/S0021-9673(97)00461-5.

Li, Y., Guo, C., Yang, J., Wei, J., Xu, J., \& Cheng, S. (2006). Evaluation of antioxidant properties of pomegranate peel extract in comparison with pomegranate pulp extract. Food Chemistry. https://doi.org/10.1016/j.foodchem.2005.02.033.

Lüle, F., \& Koyuncu, T. (2015). Convective and Microwave Drying Characteristics of Sorbus Fruits (Sorbus domestica L.). Procedia Social and Behavioral Sciences. https://doi.org/10.1016/j.sbspro.2015.06.467.

Martins, N., Barros, L., Buelga, C., Henriques, M., Silva, S. Ve Ferreiara I. (2015). Evaluation of bioactive properties and phenolic compounds in different extracts prepared from Salvia officinalis L..Food Chemistry, 170: 378-385.

Mikulic-Petkovsek, M., Schmitzer, V., Slatnar, A., Stampar, F., \& Veberic, R. (2012). Composition of Sugars, Organic Acids, and Total Phenolics in 25 Wild or Cultivated Berry Species. Journal of Food Science. https://doi.org/10.1111/j.17503841.2012.02896.x

Pérez-Jiménez, J. Ve Saura-Calixto, F. (2006). Effect of solvent and certain food constituents on different antioxidant capacity assays. Food Research International, 39(7):791-800.

Razina, T. G., Zueva, E. P., Ulrich, A. V., Rybalkina, O. Y., Chaikovskii, A. V., Isaikina, N. V., ... Zyuz’Kov, G. N. (2016). Antitumor effects of Sorbus aucuparia L. Extract highly saturated with anthocyans and their mechanisms. Bulletin of Experimental Biology and Medicine. https://doi.org/10.1007/s10517-016-3554-4

Roby, M. H. H., Sarhan, M. A., Selim, K. A., Khalel, K. I. (2013). Evaluation of antioxidant activity, total phenols and phenolic compounds in thyme (Thymus vulgaris L.), sage (Salvia officinalis L.) and marjoram (Origanum majorana L.) extracts. Industrial Crops and Products, 43, 827-831.

Salem, I. B., Fekih, S., Sghaier, H., Bousselmi, M., Saidi, M., Landoulsi, A., Fattouch, S. (2013). Effect of ionising radiation on polyphenolic content and antioxidant potential of parathon- treated sage (Salvia officinalis) leaves. Food Chemistry, 141, 13981405.

Sánchez-Moreno, C. (2002). Methods Used to Evaluate the Free Radical Scavenging Activity in Foods and Biological Systems. Food Science and Technology International. https://doi.org/10.1106/108201302026770.

Šavikin, K. P., Zdunić, G. M., Krstić-Milošević, D. B., Šircelj, H. J., Stešević, D. D., \& Pljevljakušić, D. S. (2017). Sorbus aucuparia and Sorbus aria as a Source of Antioxidant Phenolics, Tocopherols, and Pigments. Chemistry and Biodiversity. https://doi.org/10.1002/cbdv.20170032.9

Singleton, V. L., \& Rossi, J. A. J. (1965). Colorometry of total phenolics with phosphomolybdic-phosphotungstic acid reagents. American Journal of Enology and Viticulture. https://doi.org/10.12691/ijebb-2-1-5.

Stalikas, C. D. (2007). Extraction, separation, and detection methods for phenolic acids and flavonoids. Journal of Separation Science. https://doi.org/10.1002/jssc.200700261.

Tian, Y., Puganen, A., Alakomi, H. L., Uusitupa, A., Saarela, M., \& Yang, B. (2018). Antioxidative and antibacterial activities of aqueous ethanol extracts of berries, leaves, and branches of berry plants. Food Research International. https://doi.org/10.1016/j.foodres.2017.12.071.

Velioglu, Y. S., \& Mazza, G. (1991). Characterization of Flavonoids in Petals of Rosa damascena by HPLC and Spectral Analysis. Journal of Agricultural and Food Chemistry. https://doi.org/10.1021/jf00003a007

Vernon, L. S., Rudolf, O., \& Rosa, M. L.-R. (1999). Analysis of total phenols and other oxidation substrates and antioxidants by means of folin-ciocalteu reagent. Methods in Enzymology.

Zhishen, J., Mengcheng, T., \& Jianming, W. (1999). The determination of flavonoid contents in mulberry and their scavenging effects on superoxide radicals. Food Chemistry. https://doi.org/10.1016/S0308-8146(98)00102-2. 